\title{
Historical and Current Importance of Electron Probe Microanalysis in Space Sciences, A Retro- and Forward-looking Perspective
}

\author{
B. L. Jolliff ${ }^{1}$ and P. K. Carpenter ${ }^{1}$
}

${ }^{1}$ Department of Earth and Planetary Science, Washington University, St. Louis (WUSTL), MO, USA.

Electron Probe Microanalysis (EPMA) is today a mature analytical method used heavily in the investigation of meteoritic and planetary materials. EPMA is commonly the main analytical tool used to classify new meteorites by providing definitive information about mineral assemblage and quantitative mineral compositional data needed to specify a parent body or discern a grouping. EPMA is the main method used to provide detailed petrographic context for the materials that make up planetary suites such as lunar rocks and martian meteorites. Since the early days of Apollo sample investigations, EPMA has undergone numerous advances, leading to the diverse array of capabilities of modern instruments. In this paper, we provide a perspective on that progression of capabilities.

The pioneering work in development of the modern electron microprobe was done by Raimond Castaing in 1951 [1] in which he described an instrument with a focused electron beam of sufficient current to excite characteristic X-rays, with a spatial resolution of about $1 \mu \mathrm{m}$, and wavelength discrimination. Castaing's work included the theoretical underpinnings of matrix corrections needed for quantitative analysis. In less than a decade, the first commercial instrument would be produced by Cameca in 1958. Within another 5 years, other commercial electron microprobes were developed, and an electron-beam rastering capability was also developed to provide compositional distribution imaging, and soon thereafter, a commercial SEM. Another major development came in 1968, with the introduction of a solid-state $\mathrm{Si}(\mathrm{Li})$ or lithium-drifted silicon detector [2,3] for rapid qualitative analysis. And within a few more years, the development of thin windows for X-ray detectors extended the method to low-energy Xrays and light-element analysis. Also at this time it became apparent that the different correction algorithms produced apparent differences in compositions; however, this was resolved by use of the Bence Albee algorithm and correction factors [4].

The reason for this brief history is because in July 1969, the Apollo 11 mission would return the first samples of the Moon to Earth for analysis. The timing was thus ideal for the application of the newly emerging, but rapidly maturing EPMA instruments and techniques to be used on these new and precious but limited (mass and size) samples from the Moon. First reports of analyses of Apollo 11 samples were given at the January 1970 Apollo 11 Lunar Science Conference. Already, research on the mineralogy of lunar rocks relied heavily on the electron microprobe. Keil et al. [5], for example, reported elemental compositions of 20 minerals and glasses, including and importantly the wide range of compositions exhibited by pyroxenes, which reflect crystallization history, and a variety of Ti-bearing oxide phases, Fe metal, and others that would characterize the Apollo 11 rocks. The low oxygen fugacity of these materials was evident and they were found to lack aqueous alteration but to exhibit abundant evidence of shock. In the soil particles, meteoritic components were identified from the Ni-Fe compositions of metal inclusions in glasses. Spot analyses of some 12 or more elements were routinely done to characterize mineral compositions quantitatively. Analysis of the Apollo 11 materials led to discovery of much of the known mineralogy of lunar materials, and owing to the fact that Apollo 11 soils contain a significant proportion of plagioclase-rich, non-volcanic components, some of the key petrologic interpretations, such as the formation of the Moon's crust and mantle by density separation from a magma ocean [6]. 
Digital electronics, improvements in optical and backscattered-electron imaging systems, development of synthetic multilayer diffracting crystals for analysis of light elements, digital beam current control for increased stability, and advances in software have all contributed to improvements in EPMA capabilities and ease of use. Control software for automated corrections for x-ray interferences and use of multiple spectrometers contributed to increasingly complex analytical schemes for minerals containing many elements. Examples in our lab include the analysis of lunar RE-merrillite and monazite, analyzing as many as 8 rare-earth elements in addition to the usual 10-11 elements [7,8]. The capability of analyzing the REEs by EPMA provided great synergy to correlated SIMS (secondary ion mass spectrometry) analyses. Analysis of $\mathrm{U}, \mathrm{Th}$, and $\mathrm{Pb}$ in trace minerals such as thorite, yttrobetafite, zirconolite, and monazite can be done by EPMA for age determination [9].

Advances in recent years that affect how EPMA is used include improved X-ray imaging and the introduction of Si-drift detector (SDD) energy-dispersive, high-throughput detectors that enable rapid collection of X-ray data for imaging. Use of X-ray images to guide spot analyses is now the norm in characterizing extraterrestrial samples. Two approaches of special interest going forward are fullspectrum X-ray imaging [e.g., 10] and compositional mapping, using WDS, background-corrected X-ray images [11]. The authors acknowledge support for research from NASA, and for the EPMA laboratory at Washington University from NASA, the McDonnell Center for the Space Sciences, and the Department of Earth \& Planetary Sciences at Washington University.

\section{References}

[1] R Castaing, Ph.D. Thesis (1951) University of Paris, Publication ONERA N. 55.

[2] K Keil, Fortschr. Miner 44 (1967) p. 4-66.

[3] R Fitzgerald, K Keil, and KFJ Heinrich, Science 159 (1968) p. 528.

[4] AE Bence and AL Albee, J. Geol. 76 (1968) p. 382-403

[5] K Keil, M Prinz, and TE Bunch, Science 167 (1970) p. 597-599.

[6] JA Wood, et al., Proc. of the Apollo 11 Conf. (1970) p. 965-988.

[7] BL Jolliff, Lunar Planet. Sci. 24 (1993) p. 725-726.

[8] BL Jolliff et al., Geochim. Cosmochim. Acta 57 (1993) p. 4069-4094.

[9] SM Seddio, et al., Geochim. Cosmochim. Acta 135 (2014) p. 307-320.

[10] JJ Friel, Princeton Gamma-Tech, Inc. (2003) p. 82-85.

[11] PK Carpenter et al., Lunar Planet. Sci. 48 (2017) p. 2607.

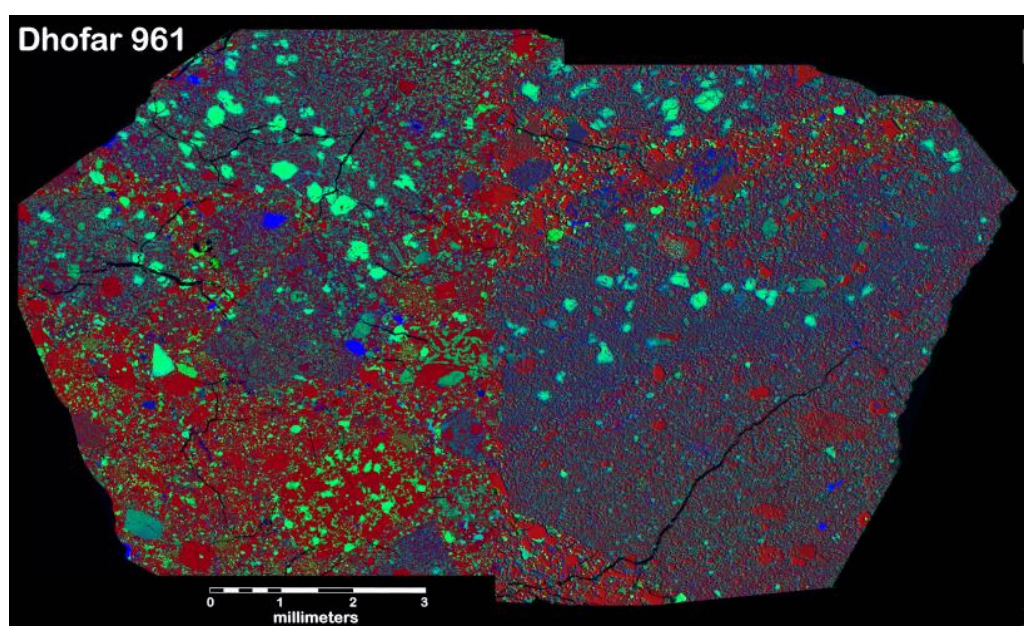

Figure 1. Example of wholesample X-ray image classification using a 3-color scheme (R: Al, G: $\mathrm{Mg}, \mathrm{B}: \mathrm{Fe})$ to distinguish major and minor phases and impact glass components in lunar meteorite Dhofar 961. Red is plagioclase, bright blue is $\mathrm{Fe}-\mathrm{Ni}$ metal, light blue and blue-green is pyroxene, green is olivine, and purple is finegrained mesostasis and impact melt (glass). 